\title{
Pembrolizumab-associated thrombotic microangiopathy in a patient with urothelial cancer: a case report and literature review
}

Manabu Hayata ${ }^{1 *}$, Masaya Shimanuki ${ }^{1}$, Takehiro Ko ${ }^{2}$, Ryosuke Date ${ }^{1}$, Ami Hamaguchi $^{1}$, Aki Tominaga ${ }^{1}$, Rei Miura ${ }^{1}$, Teruhiko Mizumoto ${ }^{1}$ and Masashi Mukoyama ${ }^{1}$

\begin{abstract}
Background: Pembrolizumab, a highly selective humanized monoclonal lgG4K isotype antibody against PD-1, is one of the immune checkpoint inhibitors approved for treatment of various cancers. The most frequent immunerelated adverse events include skin, gastrointestinal, and endocrine abnormalities. In rare cases, however, adverse events on the kidney do occur.

Case presentation: We here report a case of acute kidney injury presenting thrombocytopenia and hemolytic anemia with the presence of schistocytes, which developed in a 68-year-old man with urothelial cancer, 7 months after initiation of pembrolizumab treatment $(10$ cycles) and 3 weeks after treatment cessation. The patient had previously undergone unilateral nephrectomy and prior treatment with combined gemcitabine and carboplatin regimen. Although corticosteroid, hemodialysis, and plasma exchange were initiated, the patient died within a few days of respiratory failure. Pathological examination at autopsy revealed multiple carcinomas including the lung, liver, and spine, together with the diagnosis of thrombotic microangiopathy by electron microscopy findings of the renal tissue. To our knowledge, this is the first report describing severe thrombotic microangiopathy in a patient possibly associated with pembrolizumab, leading to death.
\end{abstract}

Conclusion: Physicians should be aware of this potential side effect in patients presenting acute kidney injury and thrombocytopenia.

Keywords: Pembrolizumab, Thrombotic microangiopathy, Acute kidney injury

\section{Introduction}

Immune checkpoint inhibitors (ICIs), monoclonal antibodies against programmed cell death 1 (PD-1) or its ligand PD-L1, and cytotoxic $\mathrm{T}$ lymphocyte-associated antigen 4 (CTLA-4) can improve outcomes in many advanced cancers, including malignant melanoma, non-

\footnotetext{
* Correspondence: hytmnb@kumamoto-u.ac.jp

'Department of Nephrology, Kumamoto University Graduate School of Medical Sciences, Kumamoto 860-8556, Japan

Full list of author information is available at the end of the article
}

small cell lung cancer, Hodgkin's lymphoma, and urothelial carcinoma. In the KEYNOTE-045 Trial [1], pembrolizumab, a highly selective humanized monoclonal IgG4 $\kappa$ isotype antibody against PD-1, showed a significant anti-tumor activity in patients with advanced urothelial carcinoma. Despite such advantage, ICIs are associated with various immune-related adverse events (irAEs) [2]. Although dermatitis, pneumonitis, colitis, hypophysitis, uveitis, hypothyroidism, and hepatitis are common irAEs, important renal events have also been

(c) The Author(s). 2020 Open Access This article is licensed under a Creative Commons Attribution 4.0 International License, which permits use, sharing, adaptation, distribution and reproduction in any medium or format, as long as you give appropriate credit to the original author(s) and the source, provide a link to the Creative Commons licence, and indicate if changes were made. The images or other third party material in this article are included in the article's Creative Commons licence, unless indicated otherwise in a credit line to the material. If material is not included in the article's Creative Commons licence and your intended use is not permitted by statutory regulation or exceeds the permitted use, you will need to obtain permission directly from the copyright holder. To view a copy of this licence, visit http://creativecommons.org/licenses/by/4.0/ The Creative Commons Public Domain Dedication waiver (http://creativecommons.org/publicdomain/zero/1.0/) applies to the data made available in this article, unless otherwise stated in a credit line to the data. 
reported. In a pooled analysis of 3695 patients treated with ICIs, Cortazar et al. reported an overall incidence rate of acute kidney injury (AKI) to be $2.2 \%$ [3]. The incidence of grade $3 \mathrm{AKI}$, defined as an increase of serum creatinine $>3 \times$ baseline or $>4.0 \mathrm{mg} / \mathrm{dL}$, or the need for renal replacement therapy, was $0.6 \%$ in total for any ICIs, with $0.9 \%$ for ipilimumab, $0.3 \%$ for nivolumab, and $0 \%$ for pembrolizumab individually [3]. Interstitial nephritis is the most common kidney-related irAE, with lupus nephritis, minimal change nephrotic syndrome, and thrombotic microangiopathy (TMA) being other renal complications [4-6].

TMA is a potentially fatal syndrome, characterized by microangiopathic hemolytic anemia, thrombocytopenia, and variable organ damage due to microcirculation thrombi formation. TMA can result from various conditions, including infection, cancer and transplantation, and from dose- and time-dependent toxicity of various drugs, such as immunosuppressive and chemotherapeutic agents and vascular endothelial growth factor (VEGF) inhibitors [7]. Plasma exchange (PE) for thrombotic thrombocytopenic purpura (TTP) or eculizumab for atypical hemolytic uremic syndrome (aHUS) has markedly improved survival from TMA. However, there are still not a few refractory cases with a high mortality rate. We here report a fulminant case of TMA who developed AKI after chemotherapy using pembrolizumab.

\section{Case report}

A 68-year-old man was diagnosed with urothelial cancer 2.5 years before, with an otherwise unremarkable medical history. The baseline serum creatinine level was 1.1 $\mathrm{mg} / \mathrm{dL}$. Transurethral resection of bladder tumor and intra-bladder pirarubicin ( $30 \mathrm{mg}$ injection) were performed for the next 10 months, when tumor recurrence in the right ureter and urinary bladder required right renal and ureteral resection with partial cystectomy 1.5 years before admission. One month after surgery, his serum creatinine level was $1.6 \mathrm{mg} / \mathrm{dL}$ without proteinuria. Two months later, metastases were identified in the left cervical and para-aortic lymph nodes. Chemotherapy was initiated using a combination of gemcitabine and carboplatin (five cycles over 5 months), with a single dose of gemcitabine of $1000 \mathrm{mg} / \mathrm{m}^{2}$ and a reduced dose of carboplatin of $194 \mathrm{mg} / \mathrm{m}^{2}$ due to chronic kidney disease (CKD) secondary to uninephrectomy.

Eight months before admission, the patient developed bilateral leg numbness, requiring a change from gemcitabine/carboplatin to intravenous pembrolizumab (200 mg every 3 weeks; 10 cycles over the course of half a year) as a second-line therapy. At treatment initiation, his serum creatinine level was $1.3 \mathrm{mg} / \mathrm{dL}$. Tumor size was temporarily reduced, along with improvement of para-aortic lymphadenopathy, but the enlargement of nodular lesion was seen in the left lung. The final cycle was given at 1 month before admission.

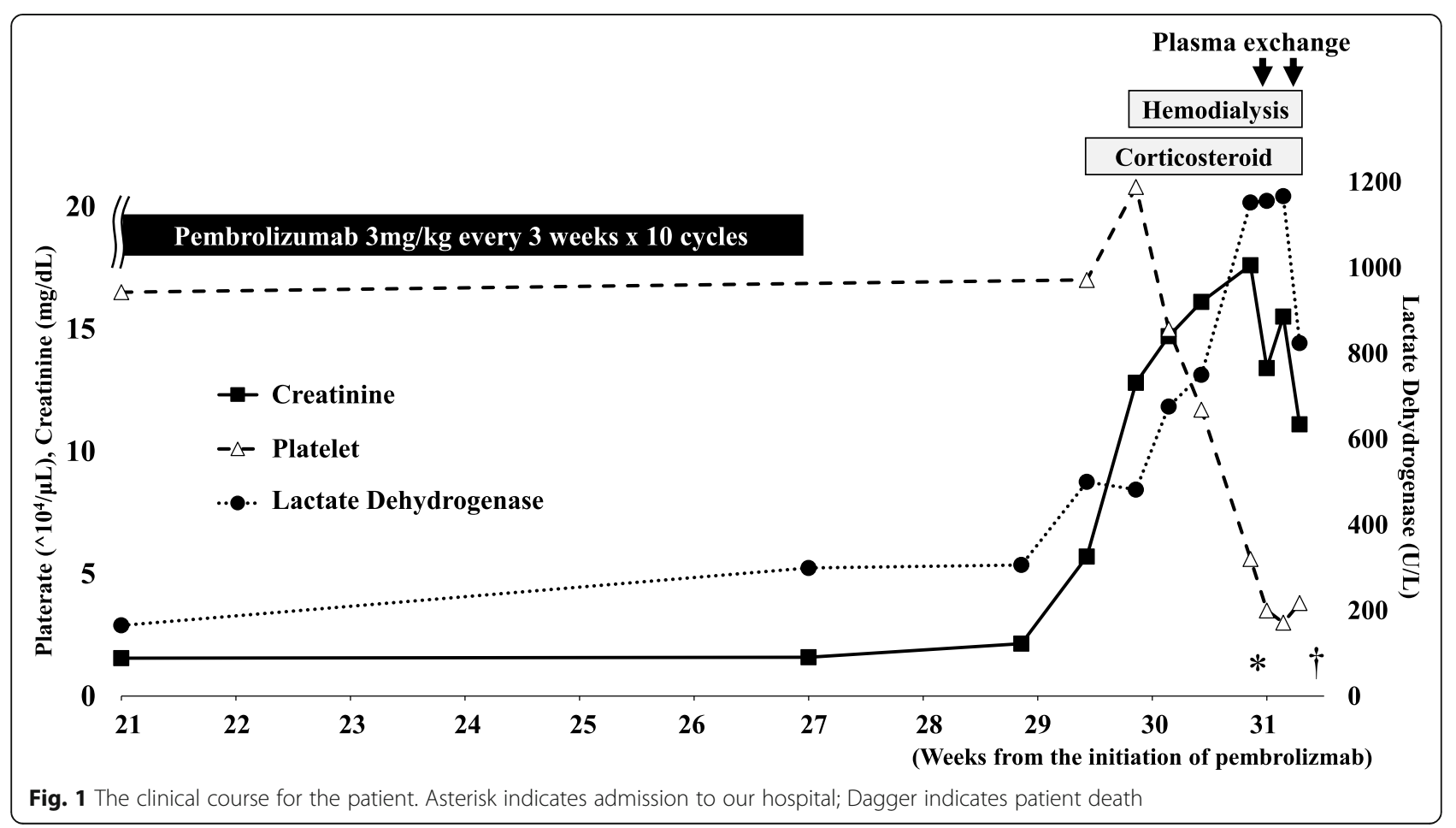


Two weeks after treatment cessation, the patient developed back pain secondary to thoracic spine metastasis. The serum creatinine level was slightly elevated to $2.1 \mathrm{mg} / \mathrm{dL}$. Four days later, the patient became anuric, with a marked elevation in serum creatinine to $5.7 \mathrm{mg} /$ dL. Grade 3 AKI was diagnosed, as defined by the Common Terminology Criteria for Adverse Events [8]. An oral dose of prednisolone $(0.9 \mathrm{mg} / \mathrm{kg})$ was administered, as per current treatment guidelines [9]. Despite treatment, his creatinine level rose to $12.8 \mathrm{mg} / \mathrm{dL} 3$ days later, when hemodialysis was initiated (Fig. 1). Over the subsequent week, his platelet concentration decreased from 150,000 to $60,000 / \mu \mathrm{L}$ and he was transferred to our department with possible TMA.

At the time of admission, the patient's Glasgow coma scale level of consciousness was assessed as E4V4M6. Physical findings were as follows: blood pressure, 147/ $85 \mathrm{mmHg}$; heart rate, $96 \mathrm{bpm}$; body temperature, $37.7^{\circ} \mathrm{C}$; body weight, $72.8 \mathrm{~kg}$; body height $169 \mathrm{~cm}$; respiratory rate, 30/min; and $\mathrm{SpO}_{2}, 99 \%$ under oxygen flow of $2 \mathrm{~L} /$ min through nasal cannula. The patient was anuric, with anemic palpebral conjunctiva and hemorrhagic spots in the oral cavity and at the site of the inguinal dialysis catheter. Lower leg edema and subcutaneous hemorrhage were observed. He had no diarrhea, indicative that Shiga toxin-associated HUS was unlikely. Medications at the time of presentation (per day) included prednisolone $60 \mathrm{mg}$, esomeprazole $10 \mathrm{mg}$, naldemedine tosylate $0.2 \mathrm{mg}$, acetaminophen $1000 \mathrm{mg}$, fexofenadine $60 \mathrm{mg}$, mitiglinide $15 \mathrm{mg}$, and sulfamethoxazole/trimethoprim $400 \mathrm{mg} / 80 \mathrm{mg}$, with darbepoetin alfa $60 \mu \mathrm{g}$ injected once a week, and fentanyl citrate patch. Laboratory data confirmed the diagnosis of TMA with AKI, with the following findings: platelet count, $35,000 / \mu \mathrm{L}$; lactate dehydrogenase, $1156 \mathrm{U} / \mathrm{L}$; hemoglobin, $8.0 \mathrm{~g} / \mathrm{dL}$; and serum creatinine, $13.4 \mathrm{mg} / \mathrm{dL}$ (Table 1 ). TMA diagnosis was consistent with findings of numerous schistocytes in a peripheral blood smear, along with anemia, negative direct Coombs test, and normal coagulation test. The ADAMTS13 (a disintegrin and metalloproteinase with thrombospondin type 1 motif, member 13) level was $38 \%$ (normal range $>10$ ), and its inhibitor was negative, suggesting that TTP was unlikely. The C-reactive protein (CRP) level was $17.0 \mathrm{mg} / \mathrm{dL}$ on admission but had been as low as $0.5 \mathrm{mg} / \mathrm{dL} 4$ days before, when thrombocytopenia had already appeared. The $\beta$-D glucan level and interferon gamma release assay were negative. Blood cultures were negative, with a lactic acid level $<2$ $\mathrm{mmol} / \mathrm{L}$. Antimicrobial treatment with meropenem was administered empirically.

The patient underwent PE $(3840 \mathrm{ml}$ fresh frozen plasma) combined with hemodialysis (HD) on days 1 and 2 post-hospitalization, with intravenous methylprednisolone $(125 \mathrm{mg})$ and red blood cell transfusion. Platelet
Table 1 Laboratory data of the patient on admission

\begin{tabular}{|c|c|c|c|}
\hline Blood biochemistry & & Blood count & \\
\hline $\mathrm{TP}, \mathrm{g} / \mathrm{dL}$ & 5.6 & $W B C, / \mu \mathrm{L}$ & 15,100 \\
\hline Alb, g/dL & 3.1 & Seg, $\%$ & 95 \\
\hline $\mathrm{Na}, \mathrm{mmol} / \mathrm{L}$ & 137 & Lymp, \% & 1.0 \\
\hline $\mathrm{K}, \mathrm{mmol} / \mathrm{L}$ & 5.5 & $\mathrm{Hb}, \mathrm{g} / \mathrm{dL}$ & 8.0 \\
\hline $\mathrm{CL}, \mathrm{mmol} / \mathrm{L}$ & 112 & Schistocytes & Positive \\
\hline $\mathrm{Ca}, \mathrm{mg} / \mathrm{dL}$ & 7.1 & Reticulocytes, \% & 13 \\
\hline $\mathbb{P}, \mathrm{mg} / \mathrm{dL}$ & 9.0 & $\mathrm{Plt}, \times 10 \wedge 4 / \mu \mathrm{L}$ & 3.5 \\
\hline BUN, mg/dL & 101 & & \\
\hline $\mathrm{Cre}, \mathrm{mg} / \mathrm{dL}$ & 13.4 & & \\
\hline T-Bil, mg/dL & 1.8 & Coagulation & \\
\hline D-Bil, mg/dL & 0.8 & PT-INR & 1.48 \\
\hline AST, U/L & 72 & APTT, \% & 44 \\
\hline$A L T, U / L$ & 22 & Fibrinogen & 256 \\
\hline$L D, U / L$ & 1156 & $\mathrm{FDP}, \mu \mathrm{g} / \mathrm{ml}$ & 42.9 \\
\hline$\gamma$-GTP, U/L & 48 & D-dimer, $\mu \mathrm{g} / \mathrm{mL}$ & 21.5 \\
\hline$A L P, U / L$ & 224 & TAT, ng/mL & 53.5 \\
\hline Amy, U/L & 175 & $\mathrm{PIC}, \mu \mathrm{g} / \mathrm{mL}$ & 0.8 \\
\hline CK, U/L & 296 & Antithrombin III, \% & 115 \\
\hline CRP, mg/dL & 17 & & \\
\hline $\mathrm{PCT}, \mathrm{ng} / \mathrm{mL}$ & 1.73 & & \\
\hline BNP, pg/mL & 513 & & \\
\hline $\operatorname{lgG}, \mathrm{mg} / \mathrm{dL}$ & 983 & Arterial blood gas & \\
\hline $\lg A, m g / d L$ & 124 & $\left(\mathrm{O}_{2} 2 \mathrm{~L} / \mathrm{min}\right.$ through nas & (cannula) \\
\hline $\operatorname{lgM}, \mathrm{mg} / \mathrm{dL}$ & 98 & $\mathrm{pH}$ & 7.41 \\
\hline $\mathrm{C} 3, \mathrm{mg} / \mathrm{dL}$ & 85 & $\mathrm{PaCO}_{2}, \mathrm{mmHg}$ & 17.9 \\
\hline $\mathrm{C} 4, \mathrm{mg} / \mathrm{dL}$ & 27 & $\mathrm{PaO}_{2}, \mathrm{mmHg}$ & 151.2 \\
\hline $\mathrm{CH} 50, \mathrm{U} / \mathrm{mL}$ & 60 & $\mathrm{HCO}_{3}{ }^{-}, \mathrm{mmol} / \mathrm{L}$ & 11 \\
\hline ADAMTS13, \% & 38 & $\mathrm{BE}, \mathrm{mmol} / \mathrm{L}$ & -12 \\
\hline ADAMTS13 inhibitor & Negative & Glu, mg/dL & 111 \\
\hline Haptoglobin, mg/dL & 3 & $\mathrm{Lac}, \mathrm{mmol} / \mathrm{L}$ & 1.31 \\
\hline
\end{tabular}

$T P$ total protein, Alb albumin, Na sodium, $K$ potassium, $C L$ chloride, $C a$ calcium, IP inorganic phosphorus, BUN blood urine nitrogen, $C r e$ creatinine, $T$-Bil total bilirubin, $D$-Bil direct bilirubin, AST aspartate aminotransferase, $A L T$ alanine aminotransferase, $L D$ lactate dehydrogenase, $\gamma$-GTP $\gamma$-glutamyl transpeptidase, $A L P$ alkaline phosphatase, Amy amylase, $C K$ creatinine kinase, CRP C-reactive protein, $P C T$ procalcitonin, $B N P$ brain natriuretic peptide, $l g$ immunoglobulin, C3 complement component 3, C4 complement component 4, CH50 50\% hemolytic complement activity, ADAMTS13 a disintegrin-like and metalloproteinase with thrombospondin type 1 motifs 13, WBC white blood cell, Neut neutrophil, Lymp lymphocyte, $\mathrm{Hb}$ hemoglobin, Plt platelet, PT-INR prothrombin time-international normalized ratio, APTT activated partial thromboplastin time, FDP fibrin degradation product, TAT thrombin antithrombin complex, $\mathrm{PIC}$ plasmin a2-plasmin inhibitor complex, $\mathrm{PaCO}_{2}$ partial pressure of carbon dioxide, $\mathrm{PaO}_{2}$ partial pressure of oxygen, $\mathrm{HCO}_{3}^{-}$ bicarbonate, $B E$ base excess, Glu glucose, Lac lactate

count recovered slightly, from 30,000 to $38,000 / \mu \mathrm{L}$. On day 2 , the patient became unconscious, then involuntary movements appeared; PE and HD were discontinued. The patient died of respiratory failure on day 3 . 


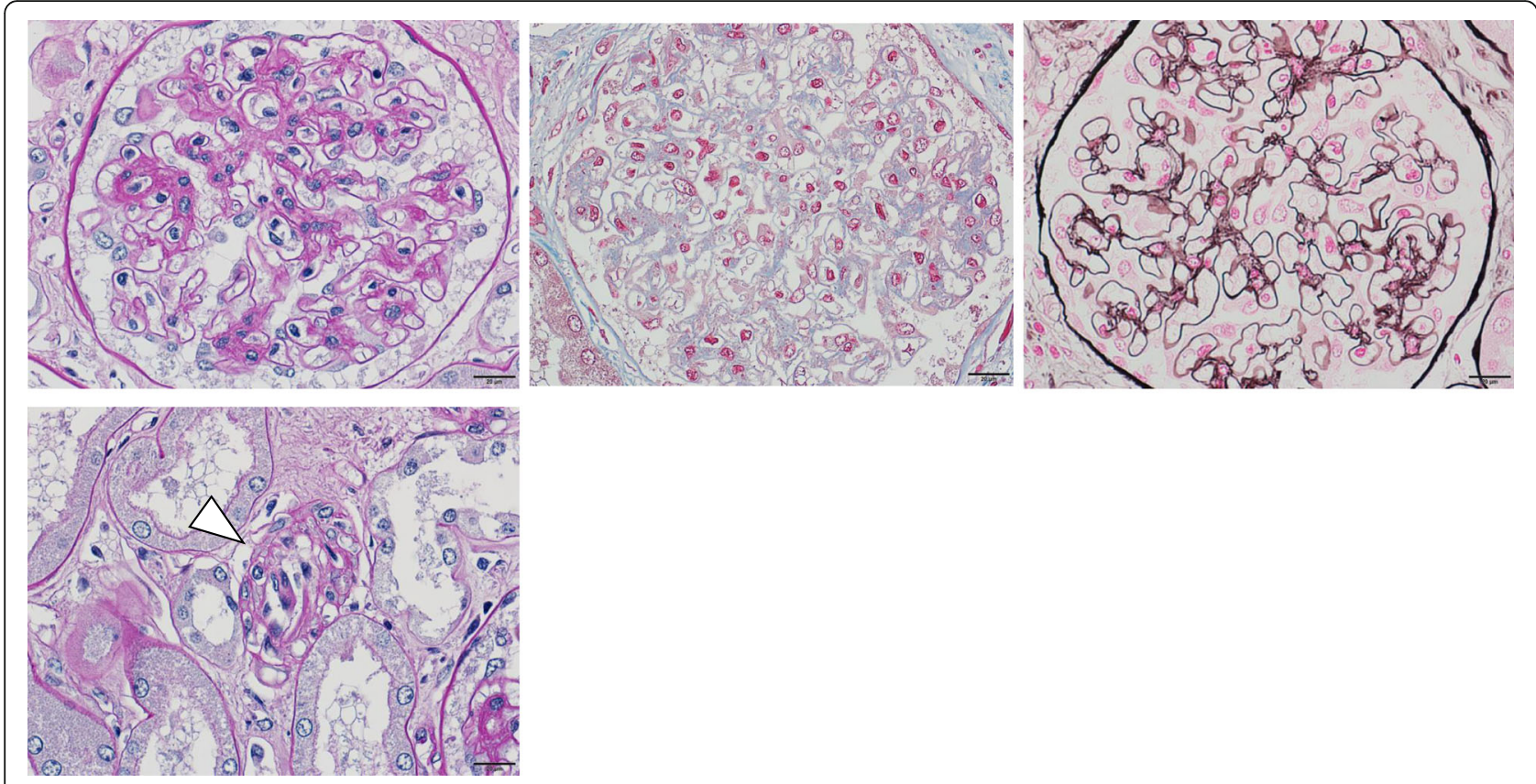

Fig. 2 Microscope examination revealed no typical findings of TMA such as mesangiolysis, fibrin thrombi, or duplication of glomerular basement membrane in glomeruli (a periodic acid-Schiff; b Azan; c periodic acid silver-methenamine). But as for arterioles, wall edema and swelling with narrowing of the lumen were observed, suggesting TMA (white arrowhead) (d periodic acid-Schiff)

Autopsy, performed $3 \mathrm{~h}$ after death, revealed pathoanatomical diagnosis of lung congestions, with multiple carcinomas in the lungs, liver, adrenal glands, and thoracic spine. Regarding kidney tissues, the glomeruli were slightly enlarged, but with no thickening, doubling, or deposition of the basement membrane, and no significant finding on immunofluorescence study. Although edema was observed in the kidney interstitium, cell infiltration was mild, with no evidence of interstitial nephritis. Mild atherosclerotic lesions were found at the level of the arcuate to interlobular arteries, but with no thrombus formation. Wall edema and swelling with narrowing of the lumen were observed in arterioles, suggesting TMA (Fig. 2). Electron microscopical examination revealed subendothelial expansion and endothelial swelling of the glomeruli, consistent with the pathological feature of TMA (Fig. 3).

\section{Discussion}

Possible mechanisms of drug-induced TMA include direct subendothelial toxicity, dysregulation of the complement pathways, decreased glomerular VEGF, and ADMTS-13 autoantibody $[7,10,11]$. Electron microscopic findings in our case indicated the possibility of direct or indirect endothelial damage, not related to VEGF inhibitors (which were not used) or ADAMTS 13 antibody. Immediate discontinuation of the offending drug together with corticosteroid administration and PE (using fresh frozen plasma) are often used as the treatment of drug-associated TMA, with the addition of immunosuppressants such as rituximab, but no clear supporting evidence has been obtained [10]. Considering the possibility of infection, immunosuppressant therapy was not possible in our case, and we proceeded with supportive care, including steroid, $\mathrm{HD}$, and $\mathrm{PE}$.

We identified one reported case of ICI-induced TMA and four reported cases of ICI-induced TTP (Table 2) $[3,12-15]$. As the causative agents, three were nivolumab and four were ipilimumab, and two cases were combinations of these two drugs. To our knowledge, TMA possibly associated with pembrolizumab has not been reported so far. The time from the last administration of ICI to the onset of TMA/TTP was between 7 and 22 days in these cases including ours. In all cases, TMA/TTP continued even after drug discontinuation. This is probably due to residual activation of $\mathrm{T}$ cells by ICI and might be a characteristic finding of ICI-related TMA. Two patients had renal impairment, one of whom was able to withdraw from dialysis but the other was dependent on dialysis. The pathologic features characterizing chemotherapy-induced TMA are vascular damage manifested by arteriolar and glomerular capillary thrombosis with abnormalities in the endothelium and vessel wall, including thickened capillary walls, occlusion of vascular lumens, fibrin deposition, and endothelial separation, with expansion of the subendothelial zone [10]. Cancer drug-induced TMA is divided into two distinct categories: types I and II [10]. Type I cancer druginduced TMA onsets usually 6-12 months after starting therapy in a dose-related manner. This type appears to 


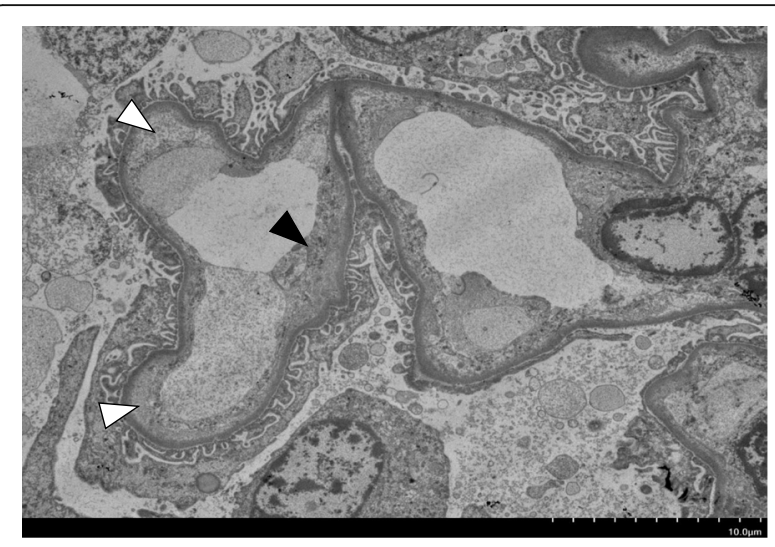

Fig. 3 Electron microscope examination showing endothelial cell enlargement and detachment from the basement membrane (black arrowhead) and subendothelial space expansion (white arrowhead) of the glomerulus

have permanent and irreversible hematologic manifestations or kidney injury. Drug characteristic of type I include mitomycin $\mathrm{C}$, gemcitabine, or platinum salts. The pathological finding is both arteriolar and glomerular capillary thrombosis in this type. On the contrary, type II cancer drug-induced TMA occurs any time after initiation of the treatment in a dose-unrelated manner. And this type has a high likelihood of recovery by stopping the drug. Drug characteristic of type II include VEGF pathway inhibitors. Glomerular capillary thrombosis lesions are exclusively found, but no arteriolar lesion in type II. We think our case was similar to type I rather than type II because irreversible thrombocytopenia and acute kidney injury persisted even after drug discontinuation and was associated with not only glomeruli but also arteriole lesions.

Due to the extent of metastases and the history of previous medications used, a direct causal relationship between TMA and pembrolizumab therapy cannot be established in our case. Although the cancer status of the patient was relatively stable, cancer-induced TMA could be another possibility, considering the fulminant course of TMA with multiple metastatic lesions. In our case, vascular endothelial damage was observed in electron microscope examination of the glomerulus, but this is a common finding of TMA and is not effective for distinguishing drug-induced TMA from TMA caused by cancer itself. However, even at the time when metastases were already observed, thrombocytopenia and kidney injury had not yet appeared. Therefore, we considered TMA in our case would be due to drug rather than cancer itself. TMA-related to use of anti-cancer agents, such as gemcitabine, typically develops 6 to 12 months after treatment initiation [10]. However, because $\mathrm{T}$ lymphocyte activation can extend over several months, irAE can occur at any time after discontinuation of ICI treatment [9]. AKI by PD-1 inhibitors is likely to occur 3-12 months after treatment initiation [5]. In our case, TMA onset was 13 months after initiation of gemcitabine/carboplatin therapy and 8 months after its discontinuation, but within 7 months of initiation of pembrolizumab treatment and 3 weeks after its discontinuation. Zupancic et al. [16] reported an increased risk for TTP with a cumulative dose of gemcitabine of $20,000 \mathrm{mg} / \mathrm{m}^{2}$; the total dose in our case was relatively small at 5000 $\mathrm{mg} / \mathrm{m}^{2}$, and the dose of carboplatin was reduced due to the previous history of renal injury. Considering the clinical course, TMA was more likely to be caused by pembrolizumab than gemcitabine/carboplatin. The possibility of secondary TMA due to infection cannot be completely denied, but platelet reduction preceded CRP elevation, suggesting that infection developed after the onset of TMA. The mechanism of the onset of TMA caused by pembrolizumab is not yet known, but according to Postow et al., four types of possible mechanisms

Table 2 Literature review of patients with ICl-related TMA/TTP

\begin{tabular}{|c|c|c|c|c|c|c|c|c|}
\hline References & Age & Sex & Malignancy & Agents & irAE & $\begin{array}{l}\text { Days since last } \\
\text { administration of } \mathrm{ICl}\end{array}$ & Treatment & Outcome \\
\hline Cortazar et al. [3] & 58 & M & Melanoma & Ipilimumab & TMA & 7 & Steroids, HD & $\begin{array}{l}\text { Dialysis- } \\
\text { dependent }\end{array}$ \\
\hline King et al. [14] & 68 & $F$ & Melanoma & Ipilimumab & TTP & 22 & $\begin{array}{l}\text { Steroids, PE, IVIG, } \\
\text { RTX }\end{array}$ & Recovered \\
\hline Youssef et al. [12] & 42 & $\mathrm{~F}$ & Renal cell carcinoma & $\begin{array}{l}\text { Nivolumab + } \\
\text { Ipilimumab }\end{array}$ & TTP & 9 & Steroids, PE & Recovered \\
\hline Honjo et al. [15] & 52 & $\mathrm{~F}$ & $\begin{array}{l}\text { Pleomorphic carcinoma } \\
\text { of lung }\end{array}$ & Nivolumab & TTP & 14 & $\begin{array}{l}\text { Steroids, MMF, } \\
\text { CHDF }\end{array}$ & Recovered \\
\hline $\begin{array}{l}\text { Lafranchi et al. } \\
\text { [13] }\end{array}$ & 70 & M & Melanoma & $\begin{array}{l}\text { Nivolumab + } \\
\text { Ipilimumab }\end{array}$ & TTP & 18 & Steroids, PE & Died \\
\hline $\begin{array}{l}\text { Hayata et al. (This } \\
\text { case) }\end{array}$ & 68 & M & Urothelial cancer & Pembrolizumab & TMA & 21 & Steroids, PE, HD & Died \\
\hline
\end{tabular}


of irAEs have been proposed: overactivation of cellular immune, increasing humoral immune, excessive inflammatory cytokine production, and enhancing complementmediated inflammation [2]. We think that our case may be included in excessive inflammatory cytokine production mechanism. However, we could not identify exact causative factor or specific signaling pathway in our case.

The pathophysiology of ICI-induced TMA is incompletely understood. Clinicians should be aware of this potential lethal complication of ICIs in patients with AKI.

\section{Abbreviations}

ICls: Immune checkpoint inhibitors; irAEs: Immune-related adverse events; AKI: Acute kidney injury; TMA: Thrombotic microangiopathy

\section{Acknowledgements}

We would like to express our gratitude to Yukimasa Kohda for his organizational evaluation and report on light microscopy and electron microscopy examinations, and Takahisa Imamura for the autopsy.

\section{Authors' contributions}

$\mathrm{MH}, \mathrm{MS}, \mathrm{TK}, \mathrm{RD}, \mathrm{AH}, \mathrm{AT}, \mathrm{RM}, \mathrm{TM}$, and MM provided discussion and treatment of the patient. $\mathrm{MH}$ collected the data and wrote the manuscript. MM reviewed and revised the manuscript. All authors read and approved the final manuscript.

\section{Funding}

No funding was obtained for this study.

\section{Availability of data and materials}

The data in the current case report is available from the corresponding author on request.

\section{Ethics approval and consent to participate}

Not applicable.

\section{Consent for publication}

Written informed consent was obtained in advance from the patient's family for the publication of this case report and any accompanying images.

\section{Competing interests}

The authors declare that they have no competing interests.

\section{Author details}

'Department of Nephrology, Kumamoto University Graduate School of Medical Sciences, Kumamoto 860-8556, Japan. ${ }^{2}$ Department of Nephrology, Tamana Central Hospital, Kumamoto 865-0064, Japan.

Received: 28 February 2020 Accepted: 29 June 2020

Published online: 06 July 2020

\section{References}

1. Bellmunt J, de Wit R, Vaughn DJ, Fradet $Y$, Lee JL, Fong L, Vogelzang NJ, Climent MA, Petrylak DP, Choueiri TK, et al. Pembrolizumab as second-line therapy for advanced urothelial carcinoma. N Engl J Med. 2017;376(11): 1015-26.

2. Postow MA, Sidlow R, Hellmann MD. Immune-related adverse events associated with immune checkpoint blockade. N Engl J Med. 2018;378(2): 158-68.

3. Cortazar FB, Marrone KA, Troxell ML, Ralto KM, Hoenig MP, Brahmer JR, Le DT, Lipson EJ, Glezerman IG, Wolchok J, et al. Clinicopathological features of acute kidney injury associated with immune checkpoint inhibitors. Kidney Int. 2016:90(3):638-47.

4. Hanna RM, Selamet U, Bui P, Sun SF, Shenouda O, Nobakht N, Barsoum M, Arman F, Rastogi A. Acute kidney injury after pembrolizumab-induced adrenalitis and adrenal insufficiency. Case Rep Nephrol Dial. 2018;8(2):171-7.

5. Jhaveri KD, Perazella MA. Adverse events associated with immune checkpoint blockade. N Engl J Med. 2018;378(12):1163.
6. Fadel F, El Karoui K, Knebelmann B. Anti-CTLA4 antibody-induced lupus nephritis. N Engl J Med. 2009:361(2):211-2.

7. George JN, Nester CM. Syndromes of thrombotic microangiopathy. N Engl J Med. 2014:371(7):654-66

8. National Cancer Institute (U.S.): Common terminology criteria for adverse events (CTCAE), Rev. edn. Bethesda, Md.: U.S. Dept. of Health and Human Services, National Institutes of Health, National Cancer Institute; 2009.

9. Brahmer JR, Lacchetti C, Schneider BJ, Atkins MB, Brassil KJ, Caterino JM, Chau I, Ernstoff MS, Gardner JM, Ginex P, et al. Management of immunerelated adverse events in patients treated with immune checkpoint inhibitor therapy: American Society of Clinical Oncology Clinical Practice Guideline. J Clin Oncol. 2018;36(17):1714-68.

10. Izzedine H, Perazella MA. Thrombotic microangiopathy, cancer, and cancer drugs. Am J Kidney Dis. 2015;66(5):857-68.

11. Eremina V, Jefferson JA, Kowalewska J, Hochster H, Haas M, Weisstuch J, Richardson C, Kopp JB, Kabir MG, Backx PH, et al. VEGF inhibition and renal thrombotic microangiopathy. N Engl J Med. 2008;358(11):1129-36.

12. Youssef A, Kasso N, Torloni AS, Stanek M, Dragovich T, Gimbel M, Mahmoud F. Thrombotic thrombocytopenic purpura due to checkpoint inhibitors. Case Rep Hematol. 2018:2018:2464619.

13. Lafranchi A, Springe D, Rupp A, Ebnother L, Zschiedrich S. Thrombotic thrombocytopenic purpura associated to dual checkpoint inhibitor therapy for metastatic melanoma. CEN Case Rep. 2020

14. King J, de la Cruz J, Lutzky J. Ipilimumab-induced thrombotic thrombocytopenic purpura (TTP). J Immunother Cancer. 2017;5:19.

15. Honjo O, Kubo T, Sugaya F, Nishizaka T, Kato K, Hirohashi Y, Takahashi $\mathrm{H}$ Torigoe T. Severe cytokine release syndrome resulting in purpura fulminans despite successful response to nivolumab therapy in a patient with pleomorphic carcinoma of the lung: a case report. J Immunother Cancer; 2019;7(1).

16. Zupancic M, Shah PC, Shah-Khan F. Gemcitabine-associated thrombotic thrombocytopenic purpura. Lancet Oncol. 2007;8(7):634-41.

\section{Publisher's Note}

Springer Nature remains neutral with regard to jurisdictional claims in published maps and institutional affiliations.

Ready to submit your research? Choose BMC and benefit from

- fast, convenient online submission

- thorough peer review by experienced researchers in your field

- rapid publication on acceptance

- support for research data, including large and complex data types

- gold Open Access which fosters wider collaboration and increased citations

- maximum visibility for your research: over $100 \mathrm{M}$ website views per year

At BMC, research is always in progress.

Learn more biomedcentral.com/submission 